\title{
Why Do People Begin to Meditate and Why Do They Continue?
}

\author{
Peter Sedlmeier ${ }^{1} \cdot$ Jan $^{\text {Theumer }}{ }^{1}$
}

Published online: 7 April 2020

(C) The Author(s) 2020

\begin{abstract}
Objectives Studies that have examined why people begin to meditate and why they stay with it are few and inconclusive. We looked at these questions in two comprehensive exploratory studies.

Methods In study 1, meditation teachers were asked why participants in their courses might begin to meditate and why they might continue to do so. A qualitative analysis of their responses, together with suggestions from the literature, yielded 77 distinct reasons that were applicable to both beginners and advanced meditators. In study 2, 245 meditators ( 49 who had practiced for less than 1 year) rated how strongly these reasons applied to themselves. Exploratory factor analyses of the reasons both to begin and to continue meditation were conducted.

Results We found a large number of different categories that go beyond those identified in previous research. Reasons changed with increasing meditation practice, although spiritual goals tended to become more important only for practitioners with a spiritual background.

Conclusions Our results indicate that reasons for meditating are much more diverse than previously assumed and that they are influenced by practitioners' spiritual background and their personality characteristics.
\end{abstract}

Keywords Reasons for meditating $\cdot$ Beginners $\cdot$ Advanced meditators $\cdot$ Spiritual background $\cdot$ Personality characteristics

There is now convincing evidence that meditation positively affects a huge variety of psychological and physiological variables, for both healthy practitioners (Sedlmeier et al., 2012, 2018) and patients (Gotink et al., 2015; Goyal et al., 2014). Given that meditation is usually practiced for at least $20 \mathrm{~min}$ per day, but often for much longer than that, it takes up a substantial amount of daily time. What motivates people to forfeit this precious time to meditate? Recent research indicates that different varieties of meditation might have different effects (Amihai \& Kozhevnikov, 2014; Dahl et al., 2015; Fox et al., 2016; Kropp \& Sedlmeier, 2019; Lumma et al., 2015; May et al., 2014; Sedlmeier, 2016). Therefore, knowing meditators' reasons or aims might turn out to be of enormous practical value: It might help guide recommendations for choosing meditation techniques that are especially suited for

Electronic supplementary material The online version of this article (https://doi.org/10.1007/s12671-020-01367-w) contains supplementary material, which is available to authorized users.

Peter Sedlmeier

peter.sedlmeier@psychologie.tu-chemnitz.de

1 Chemnitz University of Technology, 09107 Chemnitz, Germany the purpose at hand. Also, there is increasing evidence that personality factors can have a noticeable impact on whether people begin to meditate at all, as well as on the effects of meditation (e.g., Delmonte, 1988; de Vibe et al., 2015; Gu et al., 2015; Mascaro et al., 2013; Noone \& Hogan, 2018; O'Connor et al., 2012). Eventually, if meditators' reasons to begin to meditate and their personalities are known, it might be possible to predict what kind of meditation works best for a particular person.

Surprisingly, so far, there has been little research examining people's reasons for meditating. We are aware of only five studies that directly addressed this question. Shapiro (1992) asked 27 experienced meditators (mean age 35.6 years) who had signed up for an intensive Vipassana course for their primary reason for meditating and found that $37 \%$ meditated primarily because they wanted to improve self-regulation (e.g., reduce stress or pain and enhance well-being). Another $22.2 \%$ indicated that they meditated for self-exploration (e.g., increase self-awareness and self-understanding), and 33.3\% for the purpose of self-liberation (e.g., the ability to increase one's compassion or to develop a sense of harmony with the universe). With increasing meditation experience, reasons for meditating shifted from self-regulation to self-exploration and self-liberation. Participants in Shapiro's (1992) study had an 
average length of meditation experience of 4.27 years and therefore might be seen as a selective sample of meditators, in which those who were motivated to meditate for other reasons might have been absent. Moreover, although meditators could answer in an open-ended format, the answers were coded based on the three categories mentioned above.

Carmody et al. (2009) operationalized Shapiro's three categories with two items each and asked 309 participants (mean age 49.5 years) enrolled in MBSR (Mindfulness Based Stress Reduction) classes at the University of Massachusetts Medical School's Center for Mindfulness to rate their importance. All three categories received ratings close to the maximum score of 10: 9.34 for self-regulation, 8.35 for self-exploration, and 8.26 for self-liberation. However, also this sample might not be considered representative because these classes explicitly addressed participants with stress-related concerns (about half of them having been referred by their health care practitioner), and again, they were asked to rate only Shapiro's original three categories.

Netz and Schmidt (cf. Schmidt, 2014) developed a questionnaire whose items were based on informal answers regarding possible motivations for practicing meditation given by a large range of meditators. From this informal database, 58 items were derived. In an online survey, over 500 meditators judged these items on a Likert scale. After a first analysis, 31 of the items were kept, from which four factors were derived. These factors were similar to those suggested in the earlier studies: well-being, emotion regulation, self-exploration, and self-transformation. When they correlated the four factors with meditation experience (in months), the authors found a small negative correlation with well-being and a small positive one with self-transformation, which might indicate that there is some change in meditators' motivation, from more secular goals to more spiritual ones, as already suggested by Shapiro (1992).

In a more recent study, Pepping et al. (2016) asked 190 undergraduate psychology students with experience in mindfulness meditation (mean age 21.3 years) why they had started practicing mindfulness meditation and what their reasons were to continue practicing it. Only $37 \%$ of the participants reported having a current practice of mindfulness meditation (about one third of them less than 1 year), whereas the other $63 \%$ had practiced mindfulness meditation previously but no longer did so. In an online questionnaire, all participants first gave reasons why they had begun to meditate, and those with a continuing practice also reported why they continued the practice of mindfulness meditation, in an open format. Then, all participants were presented with 10 prespecified reasons for meditation to be rated on a seven-point scale (ranging from not important to very important): feel calmer, relaxation, reduce anxiety, emotion regulation, manage difficult thoughts, concentration, learning/curiosity, interpersonal relationships, reduce physical pain, and spiritual reasons. The qualitative analyses of the reasons given for beginning as well as continuing meditation revealed four categories each. Participants had begun to meditate to reduce negative experiences (94.7\%), increase their well-being (31.1\%), because some other person had motivated them (28.4\%), and for religious/ spiritual reasons $(6.3 \%)$. For those who were still practicing mindfulness meditation, the wish to reduce negative experiences remained equally strong (95.8\%). Astonishingly, and in contrast to Shapiro's (1992) results, spiritual reasons were mentioned slightly less often by those who were still practicing meditation $(4.2 \%)$, whereas with well-being, it was the reverse $(74.7 \%)$. Some members of the latter group (18.3\%) also indicated that they continued meditating because they thought it useful or beneficial. The analysis of the ratings for the 10 prespecified reasons revealed that the four top reasons were the same for beginning and continuing mindfulness meditation: feel calmer, relaxation, reduce anxiety, and regulate emotions more effectively. The only difference between meditators with less and more than 1 year of experience was that less-experienced meditators were more likely to have commenced and continued mindfulness meditation because they wanted to reduce physical pain.

Finally, a recent qualitative study (Sparby \& Ott, 2018) focused on anthroposophical meditation and obtained only a partial match with Shapiro's (1992) three topics. In part probably due to anthroposophical practitioners' special kind of spiritual background, they found predominantly spiritual themes, and their analysis yielded a classification system of three categories: internal (inside the subject, e.g., selfrealization or initiation), external ("outside" the subject, e.g., duty), and service (meditating for something or someone other than oneself, e.g., service to the world and humanity). Sparby and Ott's study nicely illustrates that meditators' motivation might not be uniform but rather strongly dependent on meditators' spiritual (or secular) background.

The five studies outlined above do not give a clear picture of why people meditate. Shapiro's original categories - self-regulation, self-exploration, and self-liberation - do not seem to exhaustively cover all possible kinds of motivations (Pepping et al., 2016; Schmidt, 2014; Sparby \& Ott, 2018). And, so far, the conclusion that motivation changes over time mainly rests on correlational evidence (Schmidt, 2014; Shapiro, 1992). In contrast, Pepping et al. (2016), who had addressed that question explicitly, even found a tendency toward the nonhypothesized direction: more experienced meditators being more interested in well-being and less in spiritual growth. Also, meditators practicing different kinds of approaches that might target different goals (e.g., Sedlmeier, 2018) were all treated alike. And finally, personality differences between meditators were never explicitly taken into account when asking for their reasons to begin and continue meditation.

The present studies attempted to overcome these limitations to arrive at a more balanced view of why people begin 
to meditate and why they continue to do so. To obtain and test a more or less exhaustive list of possible motivations for meditation, we employed a two-step procedure, similar to that used by Netz and Schmidt (Schmidt, 2014): First, we collected a comprehensive sample of possible reasons for meditating, and then, we had participants rate these reasons according to their importance. To be able to detect changes in motivation with increasing practice, we asked experienced meditators both why they began and why they continued meditation. We also compared their answers on why they began to the answers given by a sample of beginners, to get an impression of what reasons might not be fulfilled by meditation and therefore might not motivate meditators to go on with their practice. In addition, we also addressed the questions of whether practitioners' spiritual backgrounds and personalities might have an impact on their reasons for meditating.

\section{Study 1}

Who might be the most knowledgeable regarding why people begin and continue to meditate? Of course, we could ask meditators themselves, both beginners and experienced practitioners. However, to obtain an exhaustive list of reasons, the most suitable people are probably meditation teachers, who meet and talk to many meditators, both beginners and experienced practitioners. Therefore, we began our exploration by addressing meditation teachers. The resulting list of reasons for meditating, complemented by reasons mentioned in the literature, was to be used as the basis for a later systematic survey with both beginners and experienced meditators (study 2).

\section{Method}

Participants After performing a comprehensive Internet search for meditation institutions in Germany, we identified 111 that were accessible by email. From these, 28 took part in our survey, and in all cases, the respondents were meditation teachers. The majority of the respondents taught meditation in a Buddhist context $(n=17)$, two meditation teachers had a Christian background, and the other nine were not explicitly connected to any spiritual background.

Procedure In the survey, all participants were asked to respond to the following four questions: (1) Why, in your opinion, have the course participants in your institution begun to meditate? (2) Did your course participants' reasons for meditating change with continued practice? If so, when, why, and how? (3) If there are different reasons, which ones are the most frequent ones, and which ones are less frequent? And (4) do you think that the motivation to begin meditating in other institutions is the same as in your institution?
Moreover, we collected reasons for meditating from the abovementioned papers that had directly addressed the issue as well as other work (except the items from Schmidt, 2014, with which we were unfamiliar at the time), including qualitative analyses that had mentioned reasons for meditating (e.g., Campbell, 2009; Lomas et al., 2013; O'Connor et al., 2012; Miller \& Nozawa, 2005; Shapiro, 1978; Zarrabian, 2010).

Measures There were no additional measures used in study 1 .

Data Analyses The resulting list of reasons was checked for duplicates. If reasons were categorized as duplicates, the less precise and less concrete formulations were removed. If items were formulated very specifically, so that they applied only to a subset of meditators, they were dropped or reformulated (e.g., "interest in Buddhism" was reformulated as "interest in spirituality"). Also, reasons were checked as to whether they applied only to beginners, only to experienced meditators, or to both and were categorized accordingly.

\section{Results}

From the answers to the first two questions (why they began to meditate, why they continued) and the other sources mentioned above, we arrived at a list of 77 reasons that applied to both beginners and experienced meditators (for the full list, see Table S1 in the Supplementary Materials). Six additional reasons referred exclusively to the beginning phase: recommended by friends/acquaintances, recommended by doctor/ therapist, read about meditation in books/on Internet, read advertisements for meditation, practicing yoga increased my interest in meditation, and out of curiosity. Finally, four reasons were judged to be appropriate only for experienced meditators: try out new meditation methods/techniques, learn to discriminate better between thoughts and emotions that should or should not be used in actions and speech (we felt that this wish rarely if ever motivates people to begin meditation), repeat and deepen previous meditation experiences, and because my meditation teacher motivated me to continue.

All but one of the participants (who taught only beginners) stated that reasons do indeed change with increasing practice and gave some suggestions as to when, why, and how that might be the case (question 2). There was an overarching consensus that not much can be said about when exactly such changes arise, because the respective processes might be very slow and almost unnoticeable and, furthermore, might be dependent on personal and contextual circumstances. Why might reasons for meditating change? The three explanations stated most often were that this could be due to coping better with one's own problems that triggered the initial interest in meditation (seven respondents), reaching a state of inner tranquility (six respondents), and having had some meditation- 
based insights or experiences (five respondents). Other explanations included less desire for "special experiences," an increased loving attitude toward oneself, wanting to know more about oneself, and deep affection for one's teacher. One participant conjectured that beginning meditators who see their initial goals unfulfilled after some time just stop meditating.

The meditation teachers also made some suggestions as to how changes in reasons could come about. The two most prominent explanations were that once meditators can better cope with their acute problems, they are better able to seek inner freedom or direct their focus away from themselves and toward society (six respondents), and once a state of more inner tranquility or relaxation has been reached, meditators can more easily be mindful of their own emotions and thoughts (five respondents). Four respondents argued that with increasing practice, interest in spiritual issues might increase.

Most of the 17 respondents who answered the question about the most frequent reasons (question 3) referred to beginners. If they explicitly addressed reasons for continuing with meditation, most argued that the frequency distribution of possible reasons was less clear-cut for advanced meditators than for beginners. Six respondents said that people mainly begin to meditate after a life crisis, whereas none mentioned spiritual or religious reasons as the most important ones. Six respondents who compared the frequency of "personal problems" with "spiritual reasons" of meditators in their institutions concluded that the former were much more important than the latter. Another reason identified by four respondents as most important was the search for tranquility, but four respondents also suggested that reasons to begin meditation are very diverse and that it is hard to say which are the most frequent ones.

Of the 25 respondents who answered the question about whether the reasons found in their institutions are comparable with those found in other institutions (question 4), nine agreed but 12 argued that there might be systematic differences in reasons for meditating depending on the background, spiritual, or otherwise, of the institutions that teach meditation, and depending on the meditation teachers. Four participants indicated that they felt unable to answer the question.

\section{Discussion}

The main purpose of study 1 was to arrive at a comprehensive list of reasons for why people begin and continue to meditate. The analysis of the meditation teachers' responses plus suggestions from the literature yielded 87 different reasons, of which 77 could apply to both beginners and experienced meditators. Of the remaining 10 reasons, six and four were judged to be applicable only to beginners or experienced meditators, respectively. All meditation teachers were of the opinion that reasons for meditating change with increasing practice but that it cannot be said exactly when that will be the case. They suggested that such changes might take place when meditators, as a consequence of their initial meditation practice, are able to calm down or deal better with emotional problems often brought about by a life crisis. Consistent with Shapiro's (1992) findings, they also assumed that reasons might shift from self-regulation to self-exploration. Self-liberation, the third of Shapiro's categories, did not, according to the meditation teachers' responses, play an important role, at least not for beginning meditators, whereas having personal problems or searching for tranquility did. However, there was no consensus about the most important reasons even among the experts, perhaps due to the many different reasons identified in this study, pronounced differences in meditators' personalities, and contextual and spiritual differences in the offers associated with different institutions and instructors who teach meditation. Thus, the main finding of study 1 was that of a huge variety of reasons that go beyond previous summaries.

\section{Study 2}

In study 2, we used the comprehensive item list from study 1 to examine if these reasons for beginning and continuing to meditate can be summarized by fewer dimensions, and what these dimensions might be. We also wanted to see if and how these dimensions change with increasing meditation practice. In addition, we had a look at those items identified in study 1 that applied only to beginners and experienced meditators. Our expert respondents in study 1 suggested that reasons for meditating might differ depending on personality or contextual factors, such as the spiritual background of the institutions meditators chose. Therefore, we had respondents in study 2 complete a personality questionnaire and respond to several questions addressing different contextual issues. The two central research questions were as follows: Why do people begin to meditate? And are the reasons for continuing different from the reasons for beginning? In addition, we were interested in whether practitioners with different spiritual backgrounds and different personality structures also have different reasons for meditating.

\section{Method}

Participants Participants were recruited by emailing again to the 111 institutions addressed in study 1 as well as to six additional institutions of which we had not been aware before. The meditation teachers were asked to forward the invitation to participants in their courses, as well as to other meditators and meditation teachers they knew. Twenty-nine of the institutions (21 with a Buddhist, 1 with a Christian, and 7 without a specific spiritual background; 14 of the 28 in study 1) agreed 
to take part in the study, which yielded altogether 245 responses.

Forty-nine of these were classified as beginners (meditation practice less than 1 year) and 196 as experienced meditators (meditation practice of 1 year or longer). Beginners (72\% female) had an average age of 39.9 years $(\mathrm{SD}=12.8)$ and had been practicing meditation for an average of 5.4 months $(\mathrm{SD}=3.7)$, whereas experienced meditators $(61 \%$ female $)$ were on average 47.4 years old $(\mathrm{SD}=13.1)$ and had an average meditation practice of 12.5 years $(\mathrm{SD}=11.2)$.

Procedure Participants could choose between an online and a paper-and-pencil version of the survey (33 of the 245 participants chose the latter). First, they were asked whether they had been meditating for 1 year or longer, and all who answered this question in the affirmative received the version for experienced meditators; the others were presented the version for beginners. The only difference between the two versions was that the experienced meditators always had to give two judgments for all items that referred to reasons for meditating, one for why they began and one for why they meditated currently, including the four items that had been judged in study 1 to be suitable only for continuing meditation.

Before participants received the respective list of reasons derived in study 1 , they were first asked for the reasons that had motivated them to begin meditating, to find out whether the reasons found in study 1 might still constitute an incomplete list. In addition, experienced meditators were asked to indicate why they presently continued to meditate. After that, both beginners and experienced meditators rated the 77 reasons as to how important they were for them in respect to beginning to meditate, on a six-point scale, with the endpoints does not apply at all and applies completely (all materials originally in German). Experienced meditators also rated the same 77 reasons in respect to how important they were concerning their current meditation practice. When participants finished rating the reasons, they again had the opportunity to add other reasons that they felt had not been covered in the list presented to them. Then, they completed a personality inventory, and finally, they provided demographic information, including sex, age, education, and different aspects of their meditation practice.

Measures The personality inventory used was a short German version (21 items) of the Big Five Inventory (Rammstedt \& John, 2005).

Data Analyses Apart from several descriptive analyses (see below), we performed exploratory factor analyses (principal component analysis, SPSS version 25) to summarize the reasons for beginning and continuing to meditate. This kind of analysis was restricted to the responses of the experienced meditators (both for why they began and why they continued) because for the beginners, the sample size $(n=49)$ was smaller than the number of items (77). A central advantage of using the same sample for the two analyses is that the comparison between the summarized reasons for beginning and continuing to meditate is not plagued by additional error variance introduced if two different samples (one for beginners and one for experienced meditators) had been taken.

\section{Results}

Meditators' Practice and Spiritual Background Participants were asked to group their meditation technique(s) into one or more of six categories: mindfulness meditation, concentrative meditation, objectless meditation, contemplation, active/ dynamic meditation, and guided meditation. Experienced meditators were asked about both their early (when they began meditating) and their current practice. Table 1 (upper part) shows that the percentages for beginners and experienced meditators when they began meditating are not too dissimilar with the exception of contemplation, which was practiced more extensively by the experienced meditators early on, and the chi-squared test for the respective contingency table did not reach significance, $\chi^{2}(5)=9.48, p=.09$. The dissimilarity between the two groups increased somewhat when beginners' practices were compared with current practices of experienced meditators, $\chi^{2}(5)=10.77, p=.06$.

Most meditators grouped their meditation techniques into more than one category, which probably means that they did not stick to one technique. The proportion of practitioners who chose only one category decreased with increasing practice: beginners $47.7 \%$ ( 21 of 47 , of these: 7 mindfulness, 5 concentrative, 5 guided, 1 active, 2 objectless, 1 contemplation); experienced meditators when they began meditating $35.2 \%$ (64 of 182, of these: 21 mindfulness, 17 concentrative, 5 guided, 8 active, 6 objectless, 7 contemplation), and experienced meditators' current practice $22.0 \%$ (40 of 182, of these: 15 mindfulness, 14 concentrative, 3 guided, 0 active, 5 objectless, 3 contemplation).

Meditators were also asked about their spiritual background, and their answers were grouped into four categories: Buddhist, Hindu, other spiritual background, and no spiritual background (Table 1, lower part). Experienced meditators were only asked about their current spiritual background, and this differed markedly from that of the beginners, $\chi^{2}(3)=19.76, p=.0002$.

Why Begin? It turned out that the reasons participants added in the open-format question before and after rating the 77 reasons in the prespecified list were merely variations of the latter and did not introduce new topics or themes. The mean ratings for the six extra reasons why people might begin to meditate are given in Fig. 1, for both experienced meditators and beginners, who were quite similar. The only variable rated above the mean 
Table 1 Division of meditators into six categories of meditation (multiple answers possible) and four categories of spiritual background. Given are percentages and absolute frequencies (in parentheses)

\begin{tabular}{lcll}
\hline Variable & Beginners & Experienced meditators when they began & Experienced meditators now \\
\hline \multicolumn{2}{l}{ Category of meditation } & & \\
Mindfulness & $55 \%(26)$ & $57 \%(103)$ & $68 \%(123)$ \\
Concentrative & $47 \%(22)$ & $42 \%(77)$ & $56 \%(102)$ \\
Guided & $28 \%(13)$ & $26 \%(48)$ & $20 \%(37)$ \\
Active/dynamic & $19 \%(9)$ & $27 \%(49)$ & $20 \%(36)$ \\
Objectless & $17 \%(8)$ & $26 \%(47)$ & $29 \%(53)$ \\
Contemplation & $4 \%(2)$ & $26 \%(48)$ & $26 \%(47)$ \\
Spiritual background & & & $44 \%(78)$ \\
None & $79 \%(37)$ & & $45 \%(81)$ \\
Buddhist & $13 \%(6)$ & & $7 \%(13)$ \\
Hindu & $4 \%(2)$ & & $4 \%(7)$ \\
Other & $4 \%(2)$ & & \\
\hline
\end{tabular}

For category of meditation: beginners, $n=47$; experienced meditators when they began, $n=182$; experienced meditators now, $n=182$. For spiritual background: beginners, $n=47$; experienced meditators now, $n=179$

(3.5) by both groups was "out of curiosity." Only the experienced meditators indicated that reading about meditation in a book or on the Internet had motivated them to a substantial degree to begin meditating. Reading advertisements and recommendations by a doctor or therapist had basically had no impact on meditators' motivation.

The exploratory factor analysis using the 77 common items yielded 18 factors with an eigenvalue $>1$ (68.8\% explained variance). However, after orthogonal rotation (varimax), only 11 of the 18 factors had at least two items with loadings over .3. In the following, we concentrate on these 11 factors $(54.3 \%$ explained variance) because the remaining factors have little explanatory value. But even concentrating on this subset of factors makes clear that the reasons for beginning to meditate are quite diverse (Table 2).
Two factors indicate that meditation might be used as a means to reduce something negative, that is, as a reaction to acute psychological and physical problems (factor 3, factor 9). The other factors deal with improving positive aspects: mental improvement (factor 8), long-term strategies to deal better with life (factor 1, factor 10), getting to know oneself better and getting more in contact with nature and oneself (factor 2 , factor 6), opening up and seeking nonhedonic contentment and clarity (factor 4, factor 11), seeking spiritual experiences and insights (factor 5), and increasing compassion as well as working toward liberation (factor 7).

We averaged the ratings for the items by factor (see Table 2 and Table S1 in the Supplementary Materials) to obtain a measure of how important the reasons summarized in a given factor were to the practitioners (see Fig. 2). Somewhat
Fig. 1 The importance of reasons that apply only for beginning to meditate, separately for experienced meditators ( $\geq 1$ year) and beginners $(<1$ year $)$

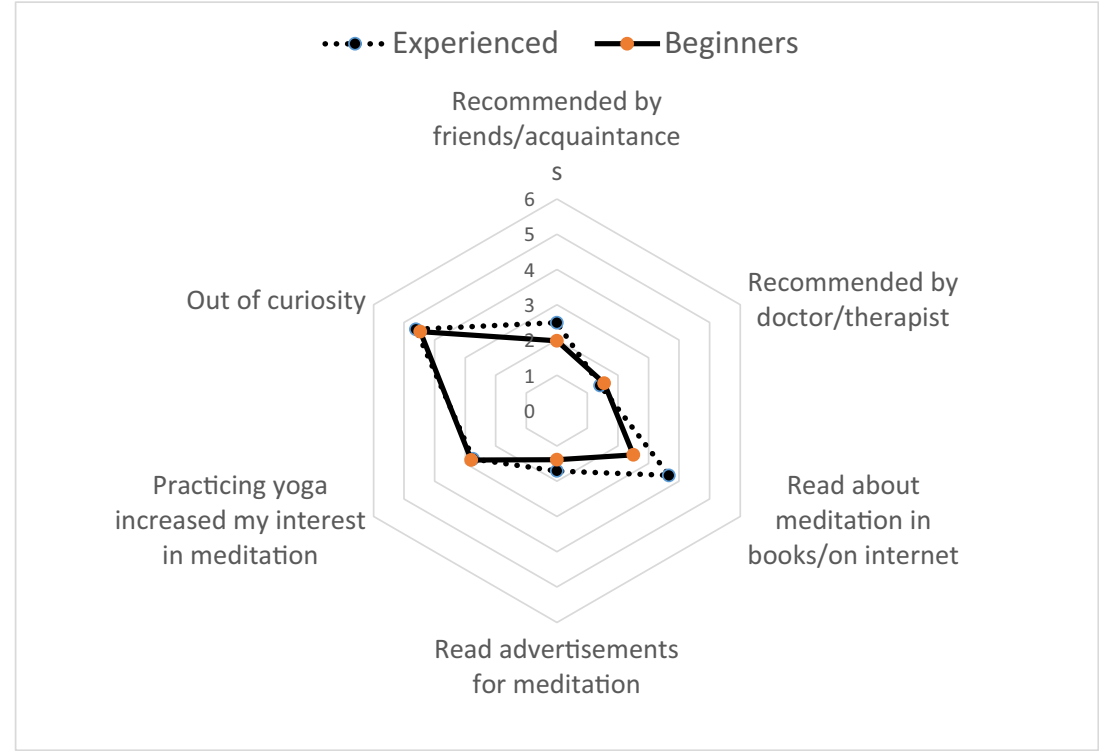


Table 2 Why do people begin to meditate? Factors ordered according to eigenvalues and variance explained, and items loading $>.3$ on these factors

Factor and item

Factor 1: calm down/feel better

Calm down internally

Relax

Find good work-life balance

Become more serene

Collect inner strength

Increase psychological well-being

Because I experience stress

Establish inner equilibrium

Factor 2: self-exploration

Explore not yet conscious aspects of my mind

Understand how my mind works

Understand why I have certain thoughts and feelings

Perceive my current thoughts

Recognize deeper causes for my actions

Obtain deeper insights about myself

Experience the volatile nature of my self

Become more sensitive for my current feelings

Interest in exploring consciousness

Develop deeper and more nuanced experiences

Factor 3: reaction to problems

Because I am feeling unhappy in my present situation

Because circumstances in my private life bother me

Because I feel that I cannot master the demands of life

Because I want to solve my problems

Because I am looking for direction in my life

Because I want to change my way of life

Factor 4: open up

Open up more to my environment

Open my heart

Accept myself

Direct my awareness to the present moment

Gain more positive attitude about myself

Improve my relationships with other people

Gain more self-confidence

Factor 5: seek spiritual experience/insight

Seek own spiritual experience

Connect to a higher power

Experience altered states of consciousness

Gain deeper insight into the laws of life

Gain alternative access to faith and spirituality

Gain deeper insight into nature of things

Factor 6: connecting with nature/self-caring

Feel connected to nature

Consciously perceive beauty of nature

Give myself more time and attention

Develop more compassion for myself

Be more aware of my body

Prevent illness
Loading

Eigenvalue (\% variance)
.79

.70

.61

.59

.56

.54

.53

.49

.73

.68

.65

.60

.59

.58

.52

.50

.48

.36

.76

.75

.57

.54

.53

.52

.71

.65

.53

.51

.39

.37

.35

.70

.68

.58

.55

.54

.48

.77

.72

.51

.44

.44

.41
$5.64(7.33)$

4.23 (5.49)

3.95 (5.13)

$3.92(5.09)$

$3.86(5.02)$ 
Table 2 (continued)

Factor and item

Seek companionship with like-minded people

Factor 7: liberation/compassion

$\begin{array}{ll}\text { Practice renunciation } & .76\end{array}$

For the benefit of all sentient beings $\quad .55$

Seek enlightenment $\quad .53$

Gain permanent liberation from all suffering $\quad .51$

Do something meaningful in my spare time $\quad .51$

Have more compassion for others $\quad .46$

Contribute to a change in society by meditating $\quad .40$

Factor 8: mental improvement

$\begin{array}{ll}\text { Improve my intellectual capabilities } & .78\end{array}$

$\begin{array}{ll}\text { Become more creative } & .53\end{array}$

Become aware of my potential $\quad .51$

Improve my concentration $\quad$.51

Improve professional competencies $\quad .50$

Factor 9: deal better with problems

Deal better with grief

Learn to deal better with pain $\quad .64$

Learn to deal better with physical ailment $\quad .62$

Factor 10: personal development

$\begin{array}{ll}\text { Personal development } & .57\end{array}$

$\begin{array}{ll}\text { Recognize and remove negative thoughts and beliefs } & .49\end{array}$

Make my mind familiar with new positive thoughts and images $\quad .46$

Deal better with my feelings $\quad .45$

Factor 11: contentment and clarity

Experience deep contentment and inner happiness in the present $\quad .69$

Become more open to new experiences $\quad .59$

$\begin{array}{ll}\text { Experience inner clarity } & .47\end{array}$

Fig. 2 Reasons for beginning to meditate: average ratings for items by factor $(1=$ does not apply at all and $6=$ applies completely). Factor numbers (F; see Table 2) are given in parentheses

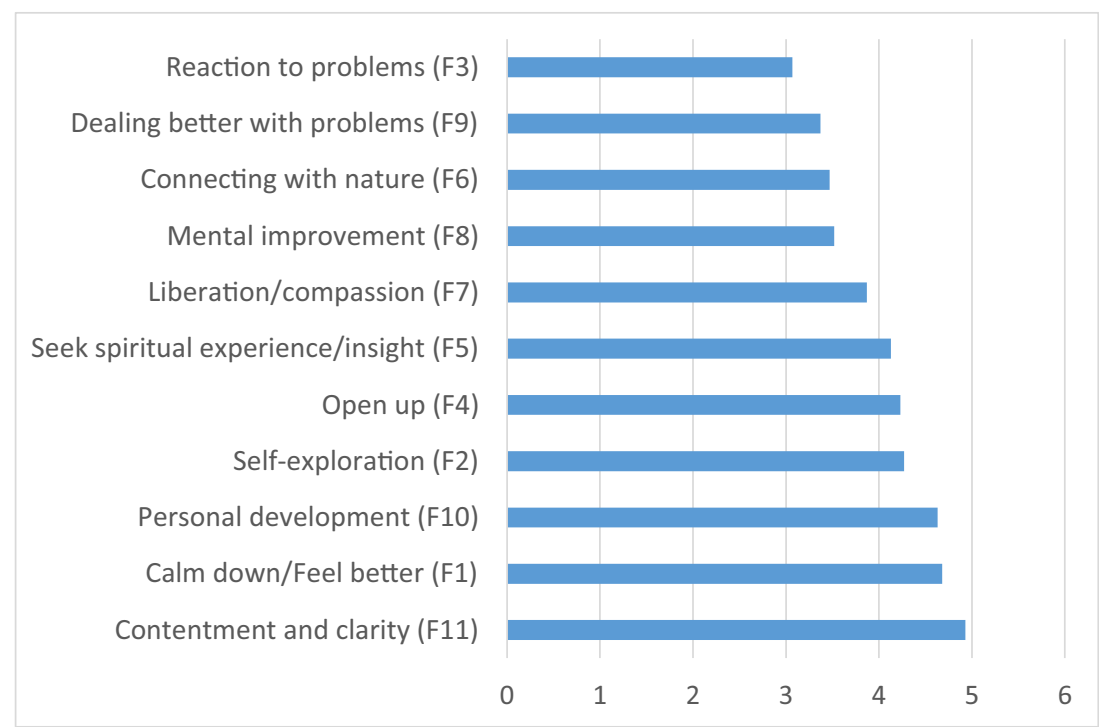


surprisingly, meditation as a means to overcome problems was rated least important, whereas positive aspects such as personal development, calming down, and eudaemonic well-being (contentment and clarity) received the highest ratings. Spiritual reasons were judged as of medium importance.

Note that the above analyses refer to retrospective judgments of experienced meditators with an average meditation practice of almost 13 years. To check whether the retrospective reasons of experienced meditators agree with the reasons of the beginners, we calculated the correlation between the mean ratings of both groups across the 77 items and obtained $r=.72$. This is a large correlation but still far from perfect. After all, the experienced meditators still meditated, and some of the beginners might have opted out of meditating before they reached the 1-year mark, which we took as our cutoff. Table 3 shows the differences between the ratings of experienced meditators and beginners for the 10 items with the largest negative (more important for beginners than experienced meditators) and positive (more important for experienced meditators) differences. The results of this analysis indeed indicate that the experienced meditators who provided the data for the factor analysis might have been a somewhat selected sample of all people who begin to meditate. This is especially visible in the reasons that were more important for them than for the beginners (lower part of Table 3). At the beginning of their meditation practice, they were more interested in issues of self-transformation, such as seeking enlightenment or spiritual experiences, or developing more compassion for others. In contrast, for the sample of beginners, getting rid of negative aspects of life, such as feeling unhappy in one's present situation or experiencing stress and sleeping badly, was more important (upper part of Table 3).

Why Continue? As with the reasons for beginning meditation, the open-format answers of experienced meditators to why they continued meditating did not add aspects that were not already covered by the reasons identified in study 1 . There, we had identified four items that referred only to why practitioners continued to meditate. Two of these were seen as important (repeat and deepen previous meditation experiences, $M=5.18$ on a scale of 1 to 6 ; learn to discriminate better between thoughts and emotions that should or should not be used in actions and speech, $M=4.63$ ), whereas the other two (try out new meditation methods/techniques, $M=$ 2.61; because my meditation teacher motivated me, $M=2.5$ ) were regarded as rather unimportant by experienced meditators.

For the exploratory factor analysis, we again concentrated on the 77 common items, which also this time yielded 18 factors with an eigenvalue $>1$ ( $70.2 \%$ explained variance). Using the same selection rule as before (only factors with at least two items with loadings over .3 after orthogonal
Table 3 Why begin meditating? Differences between ratings of beginners and experienced meditators for the 10 reasons each with the highest negative (beginners value these reasons more than experienced meditators) and positive (the reverse) differences, of the 77 common reasons

\begin{tabular}{ll}
\hline Reason & Experienced minus beginners \\
\hline More important for beginners & \\
Because circumstances in my private life bother me & 1.0 \\
Because I am feeling unhappy in my present situation & -0.9 \\
Because I experience stress & -0.6 \\
Sleep better & -0.5 \\
Because I feel that I cannot master the demands of life & -0.5 \\
Increase psychological well-being & -0.4 \\
Do something meaningful in my spare time & -0.3 \\
Relax & -0.3 \\
Because circumstances in my professional life bother me & -0.2 \\
Enjoy life & -0.2 \\
More important for experienced meditators & \\
Search for meaningful motivation for life & 1.3 \\
Open up my heart & 1.3 \\
Seek enlightenment & 1.4 \\
Contribute to a change in society by meditating & 1.4 \\
Gain permanent liberation from all suffering & 1.5 \\
Gain deeper insight into the laws of life & 1.5 \\
For the benefit of all sentient beings & 1.6 \\
Seek own spiritual experience & 1.7 \\
Gain deeper insight into nature of things & 1.7 \\
Have more compassion for others & 1.8 \\
\hline
\end{tabular}


rotation), we obtained 13 factors (59.9\% explained variance) on which we will concentrate in the following (Table 4).

Again, we found people meditated as a means to reduce something negative (factor 2) or unsatisfactory (factor 8), although this time factor 2 , which we termed dealing with problems, contains a much more heterogeneous mixture of items than found in the roughly corresponding factors 3 and 9 that summarized the same respondents' reasons for beginning to meditate (Table 2). There is a new factor for this topic (factor 9), which covers physical problems and the fear of death. Two factors relate to meditation as a means to more enjoyment of life and nature (factors 12 and 13), and two address personal and mental development (factors 6 and 7). The topic of caring comes up in two other factors: once for others (factor 4) and once for oneself (factor 5). Meditation is also seen as a means for alleviating changes in life (factor 10) and for opening up to new and alternative views of life (factor 11). Calming down (factor 3 ) and seeking spiritual insights and experiences (factor 1) complete the picture.

We averaged the ratings per factor (see Table 4 and Table S1) to obtain a measure of how important the reasons summarized in a given factor were for continuing with meditation (Fig. 3). First, a comparison of Figs. 2 and 3 indicates that experienced meditators felt somewhat less strong about their current reasons to meditate than about the reasons that led them begin (an overall difference of about 0.5 points on the six-point rating scale). In addition, the ordering of the factors for continuing meditation is less clear than that for beginning to meditate, although there are some commonalities. Overcoming physical problems was on average judged least important and personal development as well as calming down as most important. Opening up and seeking spiritual experiences and insights again received medium ratings.

We also looked at changes within the sample of experienced meditators. Which individual reasons grew and which diminished in importance over time? Table 5 shows the somewhat surprising results. Some of the most highly valued reasons for continuing compared with beginning to meditate are quite pragmatic such as doing something meaningful in one's spare time, enjoying life or sleeping better, or consciously perceiving the beauty of nature, although also the practice of renunciation is valued more highly as a reason for continuing to meditate. In contrast, the "classic" reasons for meditating such as seeking enlightenment or spiritual experiences seem to have been more pronounced when meditators began their practice than as a reason to continue.

Does the Spiritual Background Matter? Because the small number of beginners who indicated that they had some spiritual background (see Table 1, lower part) did not allow for a sound comparison and because the number of experienced meditators who had a spiritual background other than Buddhist was relatively small (Table 1), we considered only experienced meditators practicing in a Buddhist context $(n=$
81) and experienced practitioners with no spiritual background $(n=78)$. Moreover, because respondents were asked about their present spiritual background, we concentrated on the reasons for continuing to meditate (because the background might have changed over time). To assess the similarity of the two groups, we used the average ratings for the 77 common items. The correlation between the two groups over these items was $r=.87$, indicating that the advanced meditators were more similar in respect to their reasons for continuing to meditate, irrespective of their spiritual background, than beginners and advanced meditators were in respect to their reasons for beginning to meditate $(r=.72$, see above). The difference between the two correlations yields a significant test result: $z=2.59, p=.0097$.

However, there are still some trends of differences between the two groups of experienced meditators, exemplified in Table 6. Topics that can be connected to Buddhism such as gaining liberation from all suffering and having more compassion for others were stronger for meditators with a Buddhist background, whereas long-term meditators with no spiritual background were more motivated to continue meditation for reasons such as being more aware of their body, relaxing, or consciously perceiving the beauty of nature.

Whether meditators had a spiritual background or not also covaried with time spent meditating. Whereas experienced meditators with a Buddhist background who answered the respective questions $(n=80)$ spent on average $34 \mathrm{~min}$ for one sitting and meditated $290 \mathrm{~min}$ per week, the respective figures for experienced meditators without a spiritual background $(n=78)$ were $29 \mathrm{~min}$ and $176 \mathrm{~min}$. Moreover, time spent in meditation also depended on whether respondents were beginners (on average $23 \mathrm{~min}$ per sitting and $72 \mathrm{~min}$ per week) or experienced meditators (on average $33 \mathrm{~min}$ per sitting and $247 \mathrm{~min}$ per week). If only the mean values for beginners and experienced meditators without a spiritual background (for differences see Table 7) are correlated across the 77 common items, the correlation again rises to $r=.86$. Thus, the smaller similarity between beginners and experienced meditators cannot be attributed to experience but might be due to spiritual background.

Does Personality Matter? To see whether personality has an impact on which reasons are more important for beginning and continuing meditation, we correlated participants' Big Five scores with the factor scores, for the results of both factor analyses. All correlations are based on $n=186$ experienced meditators from whom we had obtained all necessary data.

Let us first look at the connections between personality and the reasons for beginning to meditate. We restrict the presentation of results to correlations that reached significance with a two-tailed $\alpha=.05$. The more extroverted practitioners tended to meditate because they wanted to calm down (factor 1, $r=.19$ ), and they were somewhat less motivated to use meditation for personal development 
Table 4 Why do people continue to meditate? Factors ordered according to eigenvalues and variance explained, and items loading $<.3$

Factors and items

Loading

Eigenvalue (\% variance)

Factor 1: spiritual insight/experience

$7.03(9.13)$

Gain deeper insight into nature of things

.75

$\begin{array}{ll}\text { Experience altered states of consciousness } & .74 \text {. }\end{array}$

$\begin{array}{ll}\text { Seek enlightenment } & .74\end{array}$

$\begin{array}{ll}\text { Gain deeper insight into the laws of life } & .73\end{array}$

$\begin{array}{ll}\text { Connect to a higher power } & .65\end{array}$

Seek own spiritual experience $\quad .65$

Explore not yet conscious aspects of my mind $\quad .58$

Obtain deeper insights about myself $\quad .56$

Widen my mental horizon $\quad .50$

$\begin{array}{ll}\text { Gain alternative access to faith and spirituality } & .50\end{array}$

Interest in exploring consciousness $\quad .50$

Develop deeper more nuanced experiences $\quad .44$

Factor 2: dealing with problems

$6.36(8.26)$

Deal better with my feelings

Because circumstances in my private life bother me $\quad .68$

$\begin{array}{ll}\text { Deal better with grief } & .62\end{array}$

$\begin{array}{ll}\text { Because I feel that I cannot master the demands of life } & .59\end{array}$

$\begin{array}{ll}\text { Accept myself } & .58\end{array}$

Increase psychological well-being $\quad .58$

$\begin{array}{ll}\text { Gain more positive attitude toward myself } & .57\end{array}$

$\begin{array}{ll}\text { Understand why I have certain thoughts and feelings } & .57\end{array}$

$\begin{array}{ll}\text { Because I want to solve my problems } & .58\end{array}$

Recognize and remove negative thoughts and beliefs $\quad .46$

Better pursue important goals in my life $\quad .36$

Factor 3: calm down

$\begin{array}{ll}\text { Calm down internally } & .81\end{array}$

$\begin{array}{ll}\text { Relax } & .77\end{array}$

$\begin{array}{ll}\text { Become more serene } & .76\end{array}$

$\begin{array}{ll}\text { Because I experience stress } & .71\end{array}$

$\begin{array}{ll}\text { Because circumstances in my professional life bother me } & .59\end{array}$

Find good work-life balance $\quad .54$

Establish inner equilibrium $\quad .51$

Collect inner strength $\quad .41$

Factor 4: care for others, open up

$\begin{array}{ll}\text { Have more compassion for others } & .76\end{array}$

For the benefit of all sentient beings $\quad .69$

Contribute to a change in society by meditating $\quad .62$

Improve my relationships with other people $\quad .55$

Open up my heart $\quad .53$

Open up more to my environment $\quad .50$

Gain permanent liberation from all suffering $\quad .48$

$\begin{array}{ll}\text { Practice renunciation } & .43\end{array}$

Factor 5: self-care

$\begin{array}{ll}\text { Be more aware of my body } & .74\end{array}$

Become more sensitive to my current feelings $\quad .63$

Give myself more time and attention $\quad .60$

$\begin{array}{ll}\text { Perceive my current thoughts } & .57\end{array}$

$\begin{array}{ll}\text { Trace my current needs } & .55\end{array}$ 
Table 4 (continued)

\begin{tabular}{|c|c|c|}
\hline Factors and items & Loading & Eigenvalue (\% variance) \\
\hline Develop more compassion for myself & .55 & \\
\hline Recognize deeper causes for my actions & .45 & \\
\hline Direct my awareness to the present moment & .41 & \\
\hline Factor 6: personal development & & $3.05(3.96)$ \\
\hline Personal development & 63 & \\
\hline Experience inner clarity & .62 & \\
\hline Make my mind familiar with new positive thoughts and images & .48 & \\
\hline Factor 7: mental development & & $2.89(3.75)$ \\
\hline Improve professional competencies & .73 & \\
\hline Become more creative & .68 & \\
\hline Improve my intellectual capabilities & 63 & \\
\hline Improve my concentration & .58 & \\
\hline Factor 8: unsatisfactory life & & $2.83(3.68)$ \\
\hline Because my life does not give me fulfillment & .76 & \\
\hline Because I am feeling unhappy in my present situation & .65 & \\
\hline Because I am looking for direction in my life & .52 & \\
\hline Because I want to change my way of life & .51 & \\
\hline Factor 9: physical problems (plus fear of death) & & $2.50(3.25)$ \\
\hline Learn to deal better with physical ailment & .76 & \\
\hline Sleep better & .55 & \\
\hline Prevent illness & .54 & \\
\hline Learn to deal better with pain & .44 & \\
\hline Lose fear of death & .42 & \\
\hline Factor 10: changes in life & & $1.96(2.54)$ \\
\hline Search for meaningful motivation for life & .65 & \\
\hline Seek companionship with like-minded people & .44 & \\
\hline Factor 11: open up to new insights & & $1.82(2.36)$ \\
\hline Because I want to deal with alternative views of life & .79 & \\
\hline Become more open to new insights & .33 & \\
\hline Factor 12: enjoy life & & $1.80(2.34)$ \\
\hline Enjoy life & .76 & \\
\hline Experience deep contentment and inner happiness in the present & .56 & \\
\hline Factor 13: enjoy nature & & $1.75(2.27)$ \\
\hline Feel connected with nature & .63 & \\
\hline Consciously perceive beauty of nature & .50 & \\
\hline Total variance & & $59.87 \%$ \\
\hline
\end{tabular}

(factor 10, $r=-.19$ ). The more agreeable meditators were less inclined to use meditation as a reaction to problems (factor 3, $r=-.19$ ) and somewhat more inclined to use it for seeking spiritual experiences or insights (factor 5, $r=.20)$. The higher meditators scored on conscientiousness, the less they used meditation as a reaction to problems (factor $3, r=.29$ ) and the more to seek contentment and clarity (factor $11, r=.17$ ). In contrast, neuroticism was strongly and positively related to using meditation as a means to reduce problems (factor $3, r=.46$ ), but also as a means to calm down (factor $1, r=.15$ ). This personality factor had a negative relationship with meditation as a means for liberation and developing compassion (factor 7, $r=-.16$ ). And finally, openness was also positively related to meditation as a reaction to problems (factor $3, r=.20$ ).

In sum, it seems that personality factors can play an important role in predicting whether people begin to meditate because they want to reduce their problems with meditation (people high on openness and especially in neuroticism) or for other reasons (people high in agreeableness and conscientiousness). The effects found in the analysis with the beginners 
Fig. 3 Reasons for continuing to meditate: average ratings for items by factor $(1=$ does not apply at all and $6=$ applies completely). Factor numbers (F; see Table 4) are given in parentheses

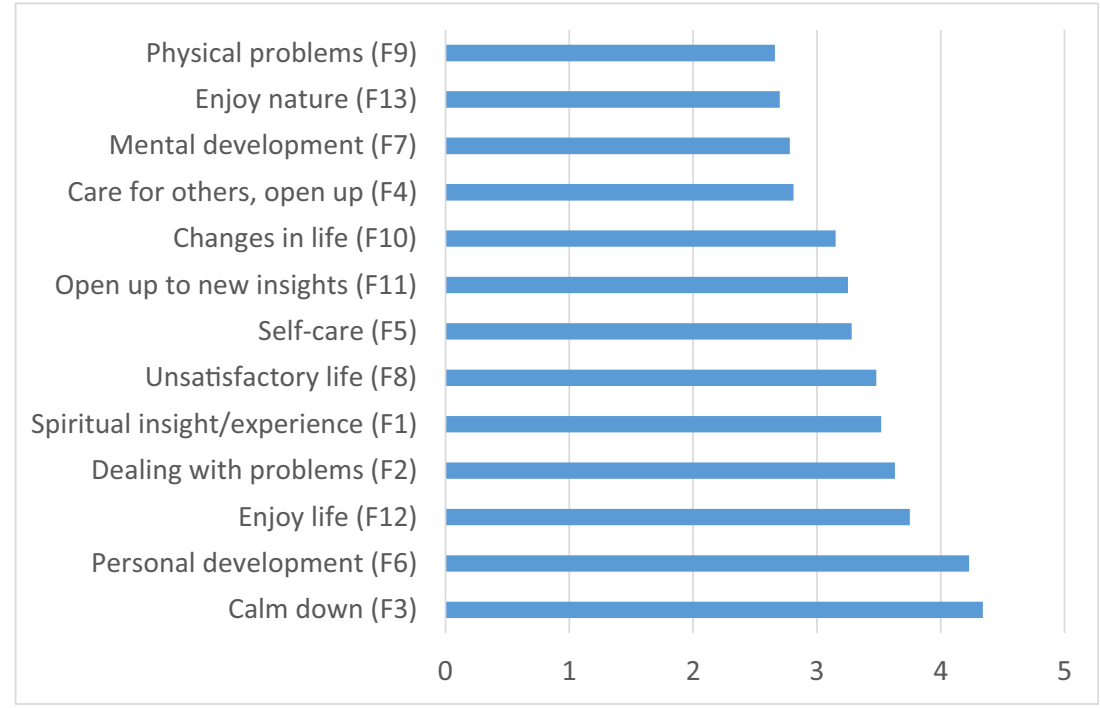

might be just a lower bound because the personality differences between the advanced meditators can be expected to have been more pronounced at the time they began their meditation practice (about 13 years ago): If one or two variables are restricted in range, correlations are usually underestimated (e.g., Stelzl, 1982). The predictive value of neuroticism is also visible in the correlations between single reasons that refer to problems in life and the neuroticism scores for the $n=49$ beginners: because I am feeling unhappy in my present situation, $r=.55$; because circumstances in my private life bother me, $r=.36$; because I feel that I cannot master the demands of life, $r=.45$; and because I want to solve my problems, $r=.41$.

Are the Big Five factors also related to the reasons that drive long-term meditators? They are, but to a lesser extent. According to our results, more extroverted practitioners are
Table 5 Differences between ratings of reasons to begin and continue meditation (experienced meditators only). Shown are the 10 reasons each with the highest negative (reasons are rated more important for continuing meditation) and positive (the reverse) differences, of the 77 common reasons

\begin{tabular}{ll}
\hline Reason & Beginning minus continuing \\
\hline More important for continuing & \\
Do something meaningful in my spare time & -1.6 \\
Practice renunciation & -1.2 \\
Enjoy life & -0.8 \\
Be more aware of my body & -0.6 \\
Sleep better & -0.5 \\
Develop more compassion for myself & -0.5 \\
Consciously perceive beauty of nature & -0.5 \\
Better pursue important goals in my life & -0.4 \\
Feel my current needs & -0.4 \\
Calm down internally & -0.4 \\
More important for beginning & \\
Gain permanent liberation from all suffering & 0.4 \\
Gain deeper insight into the laws of life & 0.4 \\
Gain deeper insight into nature of things & 0.5 \\
Seek enlightenment & 0.7 \\
Because I am looking for direction in my life & 0.7 \\
Because my life does not give me fulfillment & 0.8 \\
Gain alternative access to faith and spirituality & 0.9 \\
Seek own spiritual experience & 1.1 \\
Give myself more time and attention & 1.1 \\
Search for meaningful motivation for life & 1.1 \\
\hline
\end{tabular}


Table 6 Differences between practitioners within a Buddhist context $(n=81)$ and meditators without a spiritual background $(n=78)$, experienced meditators only. Shown are the 10 reasons each with the highest negative (reasons are rated more important by meditators without a spiritual background) and positive (the reverse) differences, of the 77 common reasons

\begin{tabular}{ll}
\hline Reason & Buddhist minus no spiritual background \\
\hline More important for practitioners without a spiritual background & \\
Be more aware of my body & -0.9 \\
Relax & -0.8 \\
Feel my current needs & -0.8 \\
Because I experience stress & -0.8 \\
Perceive my current thoughts & -0.7 \\
Consciously perceive beauty of nature & -0.7 \\
Because circumstances in my private life bother me & -0.7 \\
Give myself more time and attention & -0.6 \\
Prevent illness & -0.6 \\
Find good work-life balance & -0.6 \\
More important for practitioners with a Buddhist background & \\
Widen my mental horizon & 0.2 \\
Because I am looking for direction in my life & 0.3 \\
Because my life does not give me fulfillment & 0.4 \\
Seek companionship with like-minded people & 0.4 \\
Search for meaningful motivation for life & 0.4 \\
Have more compassion for others & 0.4 \\
Gain permanent liberation from all suffering & 0.5 \\
Lose fear of death & 0.7 \\
Do something meaningful in my spare time & 0.7 \\
Gain alternative access to faith and spirituality & 0.7 \\
\hline
\end{tabular}

less motivated by meditation as a means for facilitating changes in life (factor 10, $r=-.15$ ). Agreeableness correlates negatively with being interested in life changes $(r=-.18)$, and with wanting to calm down (factor $3, r=-.22$ ). Similar to the results for beginners, conscientiousness correlates negatively with dealing with problems (factor $2, r=-.17$ ) and with unsatisfactory life as a reason for continuing to meditate (factor $8, r=-.19$ ), but positively with personal development (factor $6, r=.16$ ). Again, neuroticism has a substantial correlation with the wish to calm down (factor $3, r=.26$ ), as well as with dealing with problems (factor $2, r=.20$ ) and with an unsatisfactory life (factor $8, r=.18$ ). Openness correlated significantly only with self-care (factor $5, r=.14$ ).

A comparison of the average Big Five scores for beginners and experienced meditators is consistent with the assumption of a differential importance of conscientiousness and especially neuroticism for predicting reasons for beginning and continuing meditation (Fig. 4). The scores for conscientiousness and neuroticism differ significantly between the two groups: conscientiousness: $t(233)=2.11$, $p=.036(M=3.77, \mathrm{SD}=0.64$ for experienced meditators and $M=3.55, \mathrm{SD}=0.71$ for beginners) and neuroticism: $t(233)=-2.63, p=.009(M=2.93, \mathrm{SD}=0.95$ for experienced meditators and $M=3.33, \mathrm{SD}=0.89$ for beginners). However, as seen above (Table 1), beginners and experienced meditators also differed in their spiritual background. What happens if only the largest group of beginners, the one without a spiritual background, is compared with experienced meditators without a spiritual background? In this case, the differences are smaller and only neuroticism approaches significance, with lower scores for experienced meditators (experienced: $M=$ 3.12, $\mathrm{SD}=0.95$; beginners: $M=3.45, \mathrm{SD}=0.77)$ : $t(113)=-1.85, p=.07$ (all $p$ values are two-tailed). This result indicates that it might not be meditation experience per se but rather spiritual background that helps meditators become more conscientious and less neurotic. To examine this question, we also compared experienced meditators with a Buddhist background to those with no spiritual background. A significant difference was found for neuroticism: The mean score for practitioners with a Buddhist background was markedly lower $(M=.2 .77$, $\mathrm{SD}=0.93)$ than for practitioners with no spiritual background $(M=3.12, \mathrm{SD}=0.95)$, with $t(157)=-2.34$, $p=.02$.

In sum, it seems that for experienced meditators, personality factors are less predictive for why they continue to meditate than for why they began, although conscientiousness and neuroticism might still be useful predictors: The less conscientious and the more neurotic, the more important meditation is as a means for dealing with problems and with an unsatisfactory life. 
Table 7 Differences between experienced meditators without a spiritual background $(n=78)$ and beginners without a spiritual background $(n=37)$. Shown are the 10 reasons each with the highest negative (reasons are rated more important by beginners) and positive (the reverse) differences, of the 77 common reasons

\begin{tabular}{lc}
\hline Reason & Experienced minus beginners \\
\hline More important for beginners & \\
Recognize deeper causes for my actions & 1.22 \\
Because my life does not give me fulfillment & -.82 \\
Do something meaningful in my spare time & -.69 \\
Sleep better & -.56 \\
Enjoy life & -.55 \\
Increase mental ability & -.50 \\
Calm down internally & -.45 \\
Collect inner strength & -.38 \\
Better pursue important goals in my life & -.35 \\
Make by mind familiar with new positive thoughts and images & -.34 \\
More important for experienced meditators & .50 \\
Because I feel that I cannot master the demands of life & .57 \\
Connect to a higher power & .57 \\
Become aware of my potential & .61 \\
Understand why I have certain thoughts and feelings & .61 \\
Because I look for orientation in my life & .64 \\
Gain deeper insight into nature of things & .74 \\
Seek enlightenment & 1.05 \\
Search for meaningful motivation for life & 1.16 \\
Seek own spiritual experience & 1.32 \\
Give myself more time and attention & \\
\hline
\end{tabular}

\section{Discussion}

Study 2 showed that reasons for meditating can be very heterogeneous, both for beginning and for staying with the practice. Reasons may change over time and they are indeed influenced by meditators' spiritual backgrounds and personalities.

Reasons for Meditating Can Be Very Heterogeneous To group meditators' reasons, we used exploratory factor analyses, and although we restricted the number of factors to meaningfully interpretable ones, we still found 11 for beginning and 13 for

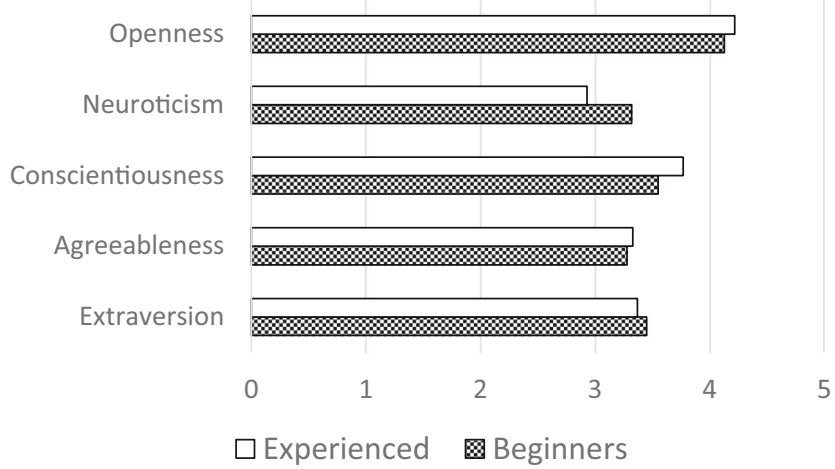

Fig. 4 Average Big Five scores: difference between beginners and experienced meditators continuing with meditation. This large number of factors indicates that people's reasons for meditating are quite varied and heterogeneous. The factors identified in study 2 partly fit with Shapiro's (1992) original scheme, which was somewhat extended by Schmidt (2014). As to the factors that summarize the reasons for beginning to meditate (Table 2), calming down and feeling better (factor 1), reacting to problems (factor 3), and dealing better with problems (factor 9) might be seen as fitting into the category of self-regulation (and Schmidt's wellbeing and emotion regulation). Our analysis also yielded a self-exploration factor (factor 2) and several factors that might be grouped into the category of self-liberation (factor 5: seek spiritual experience/insight, factor 7: liberation/compassion). However, we found other factors that do not seem to fit in the categories proposed so far, such as connecting with nature (factor 6), mental improvement (factor 8), open up (factor 4), personal development (factor 10), and seeking contentment and clarity (factor 11).

Similarly, some of the factors identified for the reasons to continue with meditation go beyond the originally suggested categories, such as enjoying nature (factor 13), mental development (factor 7), facilitating changes in life (factor 10), enjoying life (factor 12), and, again, personal development (factor 6). It seems that many meditators use meditation not only as a means to deal with psychological and physical problems, to gain more insight about themselves, and for spiritual 
reasons, but also to improve and enjoy their lives in many other ways. An especially interesting aspect is that meditation can help the meditator open up and connect to others. And indeed, the highest effect sizes found in two meta-analyses for nonclinical practitioners (Sedlmeier et al., 2012, 2018) are those for meditation's positive impact on interpersonal relationships.

Reasons for Meditating Indeed Change Over Time There was some indication in previous studies that reasons for meditating may change over time, but the evidence is largely correlation$\mathrm{al}$, that is, the importance of a given reason for meditating covaried with meditators' amount of practice (see above). But, as one of the meditation teachers in study 1 remarked, beginning meditators who see their initial goals unfulfilled might just stop meditating after some time, so these correlations suffer from the potential problem of nonsampling error (Wainer, 1999). Our data strongly indicate that long-term meditators might indeed consist of a systematically selected subsample of all people who begin to meditate (see Table 3). Long-term meditators are practitioners who either were successful in dealing with their problems or never had severe problems anyway, whereas the population of beginners arguably consists of these two groups plus a third one that eventually will give up meditation, possibly because it did not alleviate their problems or practitioners were content with the results achieved (the group not sampled in correlational studies). The percentage of practitioners who quit meditation after some time might not be so low, as exemplified in Pepping et al.'s (2016) study in which the attrition rate, that is, people who had practiced meditation some time before but no longer practiced at the time of measurement, was about two thirds! Thus, the differences we found in the personality traits of conscientiousness and neuroticism might be seen as a lower bound for the difference between the groups of dropouts and long-term meditators. On average then, long-term meditators can be expected to be less neurotic and more mature (conscientious) than beginners. However, one also has to consider that the experienced meditators in our sample were on average 7.5 years older than the beginners. If one assumes that people mature with increasing age, this difference might have partly contributed to our results.

Nonsampling error can be avoided if some kind of within design is used, such as asking experienced meditators about both why they began and why they continue. We obtained three kinds of evidence suggesting that, on average, there are indeed changes in reasons to meditate over time for the same person. The first piece of evidence comes from the two factor structures obtained for the reasons to begin and to continue meditation. The two groups of factors have many commonalities, but whereas the summarized reasons for beginning largely conform to content one might read in introductory books on meditation, the summarized reasons for continuing seem to be more varied, consistent with the observation of the meditation teachers in study 1. Advanced meditators also tended to use meditation to make their lives happier in a very pragmatic way, such as enjoying nature or enjoying life itself. Moreover, it seems that long-term meditators used meditation not only to improve their personal matters but also to open up to others (cf. Figs. 2 and 3).

Although the factors summarizing reasons for beginning and continuing meditation cannot be directly compared, singular reasons can (Table 5), the second kind of evidence. Also here, pragmatic reasons such as doing something meaningful in one's spare time, sleeping better, or more effectively pursuing important goals in one's life are more pronounced for long-term meditators than for beginners, whereas seeking enlightenment and spiritual experiences seem to have diminished in importance over time.

A third kind of evidence for changes in reasons with increasing meditation practice can be seen in the smaller impact of personality factors, presumably because long-term meditators' personalities are more stable and balanced. This, in turn, could allow practitioners the freedom to explore meditation as a means to pursue a huge variety of life-enriching goals. Such a conclusion is consistent with the explanations given by the meditation teachers in study 1 for why people continue their practice: They made progress on previous problems and have reached a state of inner tranquility. This is not to say that meditation might not have negative effects even for experienced meditators (see Lindahl et al., 2017; Tremmel \& Ott, 2016), but they can probably deal better with these effects than beginners. In sum, for long-term practitioners meditation might have ceased to be a special technique, becoming instead just a normal and well-integrated part of their daily routine that is seen as enriching many aspects of their lives, including communication with others, while not necessarily being a tool for pursuing spiritual goals such as enlightenment.

Spiritual Background Might Help Meditators Persevere Our data allowed us to compare only long-term meditators with a Buddhist background to those who indicated that they did not have any spiritual background. We found only small differences even in the reasons on which they most differed. As one probably would expect, at least some reasons that are in accordance with Buddhist theory, such as gaining permanent liberation from all suffering or having more compassion for others, were more important for practitioners with a Buddhist background. Practitioners without a spiritual background found more mundane reasons, such as being aware of one's body, relaxing, or different aspects of caring for oneself, more important. Overall, the importance given to different reasons by experienced meditators with different spiritual backgrounds seems to be quite similar, at least for the two groups compared here. But spiritual background also seems to make a difference in respect to time spent in meditation. It might be 
that having a spiritual background gives some additional motivation that helps people persevere and overcome dry spells.

Personality Can Make a Difference We found differences in conscientiousness and neuroticism between beginning and long-term meditators, and our data indicate that for beginning meditators these two personality characteristics might have some predictive value: Meditators lower in conscientiousness and higher in neuroticism were more likely to use meditation as a means to lessen their problems. This effect was still visible with experienced meditators, although to a lesser extent. We reported only the significant results, and the question of alpha errors might come up in interpreting our findings. The analysis for beginners yielded 55 correlations ( 5 personality factors $\times 11$ factors for reasons), of which 10 gained significance. If we assume that our results are totally due to alpha errors, we would expect only 3 (2.75) significant results (5\% of 55). Moreover, most alpha errors can be expected to yield small coefficients, and especially the correlations involving neuroticism were quite substantial. The alpha-error argument might be more applicable to the results for continuing meditation (10 significant results of 65), but here again, one would expect only 3 (3.25) significant results by chance alone. In sum, our results indicate that personality factors might indeed affect the reasons for beginning and, to a lesser degree, continuing meditation.

Relation to Previous Studies Our results are consistent with those found in previous studies but go beyond them in several respects. Our factor analyses also yielded similar topics (summaries of reasons for why people meditate) to those found in previous research, but we found additional topics, of which most were connected with improving and enjoying one's ordinary life in many ways.

A remarkable inconsistency in previous research is that Shapiro (1992) as well as Schmidt (2014) found indications that spiritual reasons gained in importance with increasing meditation practice whereas Pepping et al.'s (2016) results indicate the reverse. A possible explanation for this apparent paradox hinted at by our results might be that there is indeed a shift in reasons from more mundane to more spiritual ones, but only for practitioners with a spiritual background (see Table 6). Participants in Shapiro's (1992) study obviously had such as spiritual background and also Schmidt's (2014) participants might largely fall into that category, whereas for the sample of meditators examined in Pepping et al.'s (2016) survey, this seems not to have been the case. The sample of Sparby and Ott (2018), who uniquely identified service to the world and humanity as an important reason, might be regarded as an especially homogeneous group that was highly influenced by their anthroposophic background. And last, the high importance given to reducing negative experiences
(94.7\%) in Pepping et al.'s (2016) sample might be partly responsible for the high attrition rate observed there, which might have been connected to high levels of neuroticism.

Limitations and Future Research There is, of course, still the possibility that we have overlooked some important reasons for why people begin and continue meditating, but chances are that finding additional reasons might not make a substantial difference in the overall conclusions reached here. A more relevant question is to what degree our findings can be generalized. Our sample, even the beginners, were on average relatively old (beginners 39.9 years; experienced meditators 47.4 years) compared, for instance, with Pepping et al.'s (2016) sample (mean age of 21.3 years). This might have been because our sample largely comprised participants in courses offered by meditation institutions, which might not have been affordable to many young people. The sample also included only a minority of practitioners with a Hindu background. Thus, our results cannot be generalized to all meditators. This was, however, not the aim of the study. We wanted to explore the reasons that motivate people to begin and stay with meditation. Adding practitioners from other backgrounds could only increase the heterogeneity of reasons we found. In addition, we also wanted to find out whether and how strongly these reasons are influenced by contextual factors such as spiritual background and personality characteristics. Here, the inclusion of differing groups could only enhance the effects of the context.

\section{General Discussion}

We found that reasons to meditate are noticeably more varied than suggested by previous research and that the diversity of reasons might even increase with increasing meditation practice. But there are also other changes over time. Whereas for beginners, meditation seems to be frequently used as a means to reduce negative aspects of life, experienced meditators use it more to enrich their lives, which does not generally mean that they put their main emphasis on the attainment of spiritual goals. Such goals seem to be especially important for meditators with a spiritual background. Whether the spiritual background comes first or is the result of an ongoing meditation practice cannot be determined on the basis of our data, though. Personality characteristics, especially practitioners' level of neuroticism, are predictive of the reasons for meditating and such measures might be useful in alerting meditators as well as meditation teachers to the potential complication of spiritual bypassing (Fossella, 2011; Masters, 2010), which would decrease the chances 
of a successful meditation practice. One recommendation could be to alert beginners to a possible increase in the probability of prematurely stopping their meditation practice depending on personality factors and to motivate them to participate in a short screening before a meditation course. Beginning meditators with high levels of neuroticism could then be referred early on to more clinically oriented institutions that also offer meditation instruction.

Knowing why one meditates and communicating this to meditation teachers could turn out to be quite beneficial to both parties. Eventually, research on the effects of meditation might enable people to use information about the reasons for wanting to meditate to choose a technique or an approach that works best.

Acknowledgements We thank Ulrich Ott, Karin Matko, Anita Todd, Isabell Winkler, as well as three anonymous reviewers for their valuable comments on a previous version of the paper.

Author's Contributions PS designed the study, helped with the data analysis, and wrote the paper. JT executed the study and performed the first data analysis.

Funding Information Open Access funding provided by Project DEAL.

\section{Compliance with Ethical Standards}

Conflict of Interest The authors declare that they have no conflict of interest.

Open Practices Statement The data for the two studies are available from the authors on request.

Ethical Standards All studies have been approved by the ethics committee of the Faculty of Behavioral and Social Sciences of the Chemnitz University of Technology and have therefore been performed in accordance with the ethical standards laid down in the 1964 Declaration of Helsinki and its later amendments.

Open Access This article is licensed under a Creative Commons Attribution 4.0 International License, which permits use, sharing, adaptation, distribution and reproduction in any medium or format, as long as you give appropriate credit to the original author(s) and the source, provide a link to the Creative Commons licence, and indicate if changes were made. The images or other third party material in this article are included in the article's Creative Commons licence, unless indicated otherwise in a credit line to the material. If material is not included in the article's Creative Commons licence and your intended use is not permitted by statutory regulation or exceeds the permitted use, you will need to obtain permission directly from the copyright holder. To view a copy of this licence, visit http://creativecommons.org/licenses/by/4.0/.

\section{References}

Amihai, I., \& Kozhevnikov, M. (2014). Arousal vs. relaxation: a comparison of the neurophysiological and cognitive correlates of Vajrayana and Theravada meditative practices. PLoS ONE, 9. https://doi.org/ 10.1371/journal.pone.0102990.
Campbell, P. Q. (2009). Knowing body, moving mind: ritualizing and learning in two Buddhist centres in Toronto (doctoral dissertation). doi:https://doi.org/10.1093/acprof:oso/9780199793822.001.0001.

Carmody, J., Baer, R. A., Lykins, E., \& Olendzki, N. (2009). An empirical study of the mechanisms of mindfulness in a mindfulness-based stress reduction program. Journal of Clinical Psychology, 65, 613626.

Dahl, C. J., Lutz, A., \& Davidson, R. J. (2015). Reconstructing and deconstructing the self: cognitive mechanisms in meditation practice. Trends in Cognitive Sciences, 19, 515-523. https://doi.org/10. 1016/j.tics.2015.07.001

Delmonte, M. M. (1988). Personality correlates of meditation practice frequency and dropout in an outpatient population. Journal of Behavioral Medicine, 11, 593-597. https://doi.org/10.1007/ BF00844908.

de Vibe, M., Solhaug, I., Tyssen, R., Friborg, O., Rosenvinge, J. H., Sorlie, T., et al. (2015). Does personality moderate the effects of mindfulness training for medical and psychology students? Mindfulness, 6, 281-289.

Fossella, T. (2011). Human nature, Buddha nature. On spiritual bypassing, relationship, and the dharma. An interview with John Welwood by Tina Fossella. Tricycle Magazine. Retrieved from http://tricycle.org / magazine / human-nature-buddha-nature/.

Fox, K. C. R., Dixon, M. L., Nijeboer, S., Girn, M., Floman, J. L., Lifshitz, M., et al. (2016). Functional neuroanatomy of meditation: a review and meta-analysis of 78 functional neuroimaging investigations. Neuroscience and Biobehavioral Reviews, 65, 208-228.

Gotink, R. A., Chu, P., Busschbach, J. J. V., Benson, H., Fricchione, G. L., \& Hunink, M. G. M. (2015). Standardised mindfulness-based interventions in healthcare: an overview of systematic reviews and meta-analyses of RCTs. PLoS One, 10(4). https://doi.org/10.1371/ journal.pone. 0124344 .

Goyal, M., Singh, S., Sibinga, E. M., Gould, N. F., Rowland-Seymour, A., Sharma, R., et al. (2014). Meditation programs for psychological stress and well-being: a systematic review and meta-analysis. JAMA Internal Medicine, 174, 357-368.

Gu, J., Strauss, C., Bond, R., \& Cavanagh, K. (2015). How do mindfulness-based cognitive therapy and mindfulness-based stress reduction improve mental health and wellbeing? A systematic review and meta-analysis of meditation studies. Clinical Psychology Review, 37, 1-12.

Kropp, A., \& Sedlmeier, P. (2019). What makes mindfulness-based interventions effective? An examination of common components. Mindfulness, 10, 2060-2072.

Lindahl, J. R., Fisher, N. E., Cooper, D. J., Rosen, R. K., \& Britton, W. B. (2017). The varieties of contemplative experience: a mixed-methods study of meditation-related challenges in Western Buddhists. PLoS One. https://doi.org/10.1371/journal.pone.0176239.

Lomas, T., Cartwright, T., Edginton, T., \& Ridge, D. (2013). I was so done in that I just recognized it very plainly, "You need to do something": men's narratives of struggle, distress and turning to meditation. Health, 17, 191-208. https://doi.org/10.1177/ 1363459312451178.

Lumma, A.-L., Kok, B. E., \& Singer, T. (2015). Is meditation always relaxing? Investigating heart rate, heart rate variability, experienced effort and likeability during training of three types of meditation. International Journal of Psychophysiology, 97, 38-45.

Mascaro, J. S., Rilling, J. K., Negi, L. T., \& Raison, C. L. (2013). Preexisting brain function predicts subsequent practice of mindfulness and compassion meditation. NeuroImage, 69, 35-42. https://doi.org/ 10.1016/j.neuroimage.2012.12.021.

Masters, R. (2010). Spiritual bypassing: when spirituality disconnects us from what really matters. Berkeley, CA: North Atlantic Books.

May, C. J., Weyker, J. R., Spengel, S. K., Finkler, L. J., \& Hendrix, S. E. (2014). Tracking longitudinal changes in affect and mindfulness caused by concentration and loving-kindness meditation with 
hierarchical linear modeling. Mindfulness, 5, 249-258. https://doi. org/10.1007/s12671-012-0172-8.

Miller, J. P., \& Nozawa, A. (2005). Contemplative practices in teacher education. Encounter: Education for Meaning and Social Justice, $18,42-48$.

Noone, C., \& Hogan, M. J. (2018). Improvements in critical thinking performance following mindfulness meditation depend on thinking dispositions. Mindfulness, 9, 461-473.

O'Connor, L. E., Berry, J. W., Stiver, D. J., \& Rangan, R. K. (2012). Depression, guilt, and Tibetan Buddhism. Psychology, 3, 805-809. https://doi.org/10.4236/psych.2012.329122.

Pepping, C. A., Walters, B., Davis, P. J., \& O’Donovan, A. (2016). Why do people practice mindfulness? An investigation into reasons for practicing mindfulness meditation. Mindfulness, 7, 542-547.

Rammstedt, B., \& John, O. P. (2005). Kurzversion des Big Five Inventory (BFI-K). Diagnostica, 51(4), 195-206.

Schmidt, S. (2014). Opening up meditation for science: the development of a meditation classification system. In S. Schmidt \& H. Walach (Eds.), Meditation-Neuroscientific approaches and philosophical implications (pp. 137-152). Cham: Springer.

Sedlmeier, P. (2016). Die Kraft der Meditation: was die Wissenschaft darüber weiss [the power of meditation: What science knows about it]. Reinbek: Rowohlt Polaris.

Sedlmeier, P. (2018). Meditation and altered states of consciousness. Journal of Consciousness Studies, 25, 73-101.

Sedlmeier, P., Eberth, J., Schwarz, M., Zimmermann, D., Haarig, F., Jaeger, S., \& Kunze, S. (2012). The psychological effects of meditation: a meta-analysis. Psychological Bulletin, 138, 1139-1171. https://doi.org/10.1037/a0028168.
Sedlmeier, P., Loße, C., \& Quasten, L. C. (2018). Psychological effects of meditation for healthy practitioners: an update. Mindfulness, 9, 371387.

Shapiro, D. H. (1978). Behavioral and attitudinal changes resulting from a "Zen experience" workshop and Zen meditation. Journal of Humanistic Psychology, 18, 21-29. https://doi.org/10.1177/ 002216787801800303.

Shapiro, D. H. (1992). A preliminary study of long-term meditators: goals, effects, religious orientation, cognitions. Journal of Transpersonal Psychology, 24, 23-39.

Sparby, T., \& Ott, U. (2018). A qualitative study of motivations for meditation in anthroposophic practitioners. PLoS One, 13(9). https://doi. org/10.1371/journal.pone.0203184.

Stelzl, I. (1982). Fehler und Fallen der Statistik [fallacies and traps in statistics]. Bern: Hans Huber.

Tremmel, M., \& Ott, U. (2016). Negative Wirkungen von Meditation. In L. Hofmann \& P. Heise (Eds.), Spiritualität und spirituelle Krisen. Handbuch zu Theorie, Forschung und Praxis (pp. 233-243). Schattauer: Stuttgart, Germany.

Wainer, H. (1999). The most dangerous profession: a note on nonsampling error. Psychological Methods, 4, 250-256.

Zarrabian, E. (2010). The usefulness of meditation in the alleviation of self-reported depressive symptoms among young women. Unpublished doctoral dissertation, Saybrook University, Oakland, California.

Publisher's Note Springer Nature remains neutral with regard to jurisdictional claims in published maps and institutional affiliations. 